\title{
Patient-tailored effective dosing for fluoroquinolones: role of interindividual pharmacokinetic and pharmacodynamic variability
}

\author{
Oskar J Estrade ${ }^{1}$, Valvanera Vozmediano ${ }^{2}$, Nerea Carral $^{3}$, Margarita Gonzalez ${ }^{2}$, Rachel \\ Poole $^{2}$, and Elena Suarez ${ }^{3}$ \\ ${ }^{1}$ Cruces University Hospital \\ ${ }^{2}$ University of Florida \\ ${ }^{3}$ University of the Basque Country Faculty of Medicine and Nursing
}

September 29, 2021

\begin{abstract}
Fluoroquinolone's (FQs) pharmacological properties, patient characteristics, and microorganisms responsible for infection play a key role in clinical outcomes. FQs are prescribed in systemic infections due to the adequate disposition properties of the antibiotic at the site of infection. However, variability in important interindividual pharmacokinetic aspects, especially in the elimination process, may contribute to treatment failure. Likewise, today, undesired interregional variability in FQs antimicrobial activity against certain microorganisms exists. The aim of this study was to review the published information about interindividual variability in pharmacological processes for the most used FQs, such as ciprofloxacin, levofloxacin, and moxifloxacin. This review was deemed necessary on the basis of understudied interindividual pharmacokinetic and pharmacodynamic variability of FQs. The understanding of FQs dose-response relationship is critical to optimize the effectiveness of FQs therapy used to treat systemic infections. This may be particularly critical in the case of special populations such as critical ill, elderly, renal, and obese patients. The altered PK in these patients associated with creatinine clearance, together with the variability in pathogen susceptibility, associated with local resistances, may require personalized dosing regimens. Patient-tailored effective FQs dosing is needed to guarantee antimicrobial efficacy while minimizing the risk of adverse events and emergence of resistance.
\end{abstract}

\section{Hosted file}

Article_Estrade_et_al_.docx available at https://authorea.com/users/438492/articles/539687patient-tailored-effective-dosing-for-fluoroquinolones-role-of-interindividualpharmacokinetic-and-pharmacodynamic-variability

\section{Hosted file}

Table 1.pdf available at https://authorea.com/users/438492/articles/539687-patient-tailoredeffective-dosing-for-fluoroquinolones-role-of-interindividual-pharmacokinetic-andpharmacodynamic-variability

\section{Hosted file}

Table 2.pdf available at https://authorea.com/users/438492/articles/539687-patient-tailoredeffective-dosing-for-fluoroquinolones-role-of-interindividual-pharmacokinetic-andpharmacodynamic-variability

\section{Hosted file}

Table 3.pdf available at https://authorea.com/users/438492/articles/539687-patient-tailoredeffective-dosing-for-fluoroquinolones-role-of-interindividual-pharmacokinetic-and- 
pharmacodynamic-variability 